\title{
Efecto del quitosano en el control de Alternaria sp. en plantas de jitomate en invernadero
}

\author{
Carlos A. Rodríguez-Guzmán ${ }^{1}$, Ramsés R. González-Estrada ${ }^{1}$, \\ Silvia Bautista-Baños ${ }^{2}$ y Porfirio Gutiérrez-Martínez ${ }^{1}$ \\ ${ }^{1}$ Tecnológico Nacional de México/Instituto Tecnológico de Tepic. Laboratorio Integral de \\ Investigación en Alimentos. Av. Tecnológico \# 2595, Col. Lagos del Country, Tepic, Nayarit, \\ 63175, Mexico. ${ }^{2}$ Instituto Politécnico Nacional, Centro de Desarrollo de Productos Bióticos. \\ E-mail: pgutierrez@ittepic.edu.mx
}

\begin{abstract}
RESUMEN
México es el principal exportador de jitomate a nivel mundial. El uso de invernaderos favorece la protección y producción de hortalizas, sin embargo, las plántulas de jitomate son sensibles al ataque de hongos necrotróficos como Alternaria sp. y el uso de fungicidas para el control de enfermedades aunque efectivo, daña al medio ambiente y favorece la aparición de cepas resistentes, situación que impulsa a buscar alternativas seguras para el uso de fungicidas sintéticos. El quitosano posee actividad antifúngica además de la capacidad de activar mecanismos de defensa en las plantas. En este estudio, a las plantas de jitomate se les aplicó quitosano a diferentes concentraciones. Se determinó el porcentaje de daño foliar, germinación de esporas, inducción de peróxido de hidrógeno y actividad enzimática (peroxidasa y polifenoloxidasa). Se obtuvo una reducción estadísticamente significativa en el daño foliar y la germinación de esporas en plantas tratadas con $0.01 \%$ de quitosano (hasta un $80 \%$ ) en comparación con el control. La producción de $\mathrm{H}_{2} \mathrm{O}_{2}$ y la actividad enzimática fue inducida en plantas tratadas. Por lo tanto, la aplicación de quitosano puede ser una alternativa viable para el control de la pudrición causada por Alternaria sp. en jitomate.
\end{abstract}

Palabras Clave: Biopolímero, antifúngico, elicitor, protección.

\section{Effect of chitosan on the control of Alternaria sp. in tomato plants at greenhouse}

\begin{abstract}
Mexico is the main exporter of tomato worldwide. The use of greenhouses favors the protection and production of vegetables, however; tomato seedlings are sensitive to necrotrophic fungi such as Alternaria sp. The use of fungicides for disease control has been effective, however; the damage to the environment and the appearance of resistant strains leads the investigation of safe alternatives to the use of synthetic fungicides. Chitosan possesses antifungal activity in addition to the ability to activate defense mechanisms in plants. In this study, tomato seedlings were treated with chitosan at different concentrations. The percentage of foliar damage, spore's germination, induction of hydrogen peroxide and enzymatic activity (peroxidase and polyphenoloxidase) was determined. A statistically significant reduction in leaf damage and germination of spores was obtained in plants treated with $0.01 \%$ chitosan (up to $80 \%$ ) compared to the control. The production of $\mathrm{H}_{2} \mathrm{O}_{2}$ and the enzymatic activity was induced in treated plants. Thus, the application of chitosan can be a viable alternative for rot control caused by Alternaria sp. in tomato.
\end{abstract}

Key words: Biopolymer, antifungal, elicitor, protection.

Nota: Artículo recibido el 06 de abril del 2018 y aceptado el 11 de enero del 2019. 


\section{INTRODUCCIÓN}

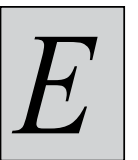

1 jitomate es la hortaliza de mayor demanda a nivel mundial(Arah etal., 2015) y México se ha convertido en el máximo exportador en el mundo, logro que en gran parte se debe al establecimiento de invernaderos, que generan alto rendimiento (SAGARPA, 2017). En Nayarit, el cultivo de jitomate es importante por su alta productividad, rentabilidad y por la superficie de siembra (INIFAP, 2008). Las enfermedades postcosecha representan un factor importante en las pérdidas durante el almacenamiento, producción y distribución del jitomate debido al deterioro de la calidad y contaminación (McGovern, 2015). Los fungicidas sintéticos se han empleado con éxito para el control de enfermedades en postcosecha, no obstante, los consumidores prefieren productos que no tengan un impacto negativo en la salud humana y el medio ambiente (Bonner \& Alavanja, 2017; Carvalho, 2017; Fagundes et al., 2013). El uso de recubrimientos puede ser una alternativa para el control de enfermedades y preservación de frutas y hortalizas. En este sentido, se han aplicado exitosamente recubrimientos a base de carbohidratos-lípidos contra Botrytis cinerea y Alternaria alternata en fruta de tomate cherry con buenos resultados (Fagundes et al., 2013). El quitosano es un polímero biodegradable, no tóxico, bioactivo, que posee actividad antifúngica y además induce mecanismos de defensa en tejidos vegetales mediante la producción de sustancias como las fitoalexinas y la activación de genes de defensa (Romanazzi et al., 2016; Jayaraj \& Punja, 2007). En un estudio en plántulas de jitomate, se aplicó quitosano para el control del Tizón temprano (Alternaria solani); los resultados mostraron un aumento en la producción de quitinasa dando lugar a una reducción en la severidad de la enfermedad (Sathiyabama et al., 2014). En un estudio reciente en hojas de espinacas tratadas con quitosano, se evidenció el aumento en la actividad enzimática de peroxidasa, catalasa y fenilalanina amonioliasa asociadas con la defensa de la planta (Singh, 2016). El objetivo de este trabajo fue evaluar la efectividad del quitosano en el control de Alternaria sp. en plantas de jitomate bajo condiciones de invernadero.

\section{MATERIALES Y MÉTOdOS \\ Material Biológico}

El hongo fitopatógeno fue previamente aislado, purificado e identificado en frutos de jitomate enfermos Saladette var. "Río grande". Los frutos se colocaron en cámaras húmedas (90-95\% $\mathrm{HR}, 30^{\circ} \mathrm{C}$ ) por 5 días con el fin de estimular el desarrollo del hongo. Posteriormente, se realizó el aislamiento que consistió en cortar secciones de tejido $\left(1 \times 1 \mathrm{~cm}^{2}\right) 50 \%$ sano y $50 \%$ con síntomas de contaminación; los tejidos fueron desinfectados en una solución de hipoclorito de sodio ( $2 \%$ ) durante 2 minutos. Los tejidos desinfectados se enjuagaron con agua destilada estéril ( 2 min) y se colocaron sobre papel filtro, tratando de eliminar la humedad. Finalmente, los tejidos se colocaron en cajas de Petri con medio de cultivo agar papa dextrosa (Bioxon) y se incubaron a $25^{\circ} \mathrm{C}$ por un periodo de 24 a 72 horas. Se procedió a realizar la purificación a partir de colonias que crecieron en la periferia de las secciones del tejido, para obtener un solo tipo de morfología por placa, se tomaron secciones de agar con micelio utilizando una aguja de disección y se colocaron en el centro de placas con medio agar papa dextrosa. Se incubaron a $25^{\circ} \mathrm{C}$ por un periodo de 24 a 72 horas hasta la observación de las colonias con características homogéneas. Las cepas purificadas se identificaron por medio de su morfología macroscópica y microscópica. Las características observadas de los conidios, se compararon con las descritas en claves dicotómicas, monografías y bases de datos de microorganismos (Barnett \& Hunter, 1998).

\section{Preparación de quitosano}

Los tratamientos con quitosano se prepararon a diferentes concentraciones $(0.01,0.05,0.1$ y $0.25 \%)$ empleando quitosano de bajo peso molecular ( $\mathrm{cp}=20-300,75-85 \%$ desacetilación $)$ (Sigma-Aldrich, MO, USA) en agua destilada ( $\mathrm{p} / \mathrm{v})$ con ácido acético al $2 \%$. Las soluciones se sometieron a agitación constante por 24 horas y fueron ajustadas a un $\mathrm{pH}$ de 5.6 con $\mathrm{NaOH}(1 \mathrm{~N})$. Finalmente, se adicionó $0.1 \mathrm{~mL}$ de Tween 80 (El Ghaouth et al., 1992).

\section{Preparación del material vegetativo}

Las semillas de jitomate tipo Saladette var. "Río Grande" fueron sembradas en charolas que contenían como sustrato turba canadiense (marca Lambert). La siembra se llevó a cabo colocando una semilla por cavidad a un centímetro de profundidad y cubierta con el sustrato. Se realizaron riegos periódicos de acuerdo a las exigencias del cultivo para su correcto desarrollo. Una vez que las plántulas alcanzaron aproximadamente $20 \mathrm{~cm}$ de altura y que la raíz de las plántulas envolvieron completamente el sustrato, fueron trasplantadas a bolsas negras conteniendo Tezontle. De igual manera se realizaron riegos periódicos para su correcto desarrollo.

\section{Aplicación de los tratamientos con quitosano}

A las plantas de jitomate de 45 días de crecimiento, se les asperjó con quitosano (10 $\mathrm{mL}$ por planta) a diferentes concentraciones $(0.01,0.05,0.1$ y $0.25 \%)$, se incluyó un control negativo que consistió en plantas asperjadas con agua destilada estéril y como control positivo plantas inoculadas con el patógeno.

\section{Análisis microscópico del efecto del quitosano en la germinación de esporas}

Para este estudio se recolectaron muestras de hojas tratadas e inoculadas (120 horas después de la inoculación), se cortaron segmentos de aproximadamente $1 \mathrm{~cm}^{2}$ y fueron transferidas a tubos con etanol frío (95\%) y ácido acético (1:1), para eliminar la clorofila de las hojas. Después de 2 días los tejidos foliares se transfirieron a ácido láctico $(80 \%)$ e incubaron a temperatura ambiente por 5 días. Los segmentos de tejido colocados en un portaobjeto fueron examinados en un microscopio óptico (marca Motic) e igual las muestras con 200 esporas a 40x (Jayaraj \& Punja, 2007). Se les consideró esporas germinadas cuando 
la longitud del tubo germinativo era igual o más largo que el diámetro de la espora (Yao et al., 2004).

Evaluación del efecto preventivo del quitosano en la severidad de la enfermedad

Las plantas tratadas con quitosano fueron inoculadas ( 10 horas después de aplicado el tratamiento), con una suspensión de conidios de Alternaria sp. (1x106/mL) (López-Mora et al., 2013) y se incubaron en una cámara húmeda (HR 80-90\%, $26^{\circ} \mathrm{C}$ ), por 72 horas. Después, las plantas se mantuvieron en un invernadero a condiciones ambientales. La severidad de la enfermedad se evaluó 20 días después de la inoculación, utilizando una escala que se basa en el porcentaje del área foliar con síntomas de amarillamiento y necrosis, de acuerdo a lo propuesto por Jayaraj \& Punja (2007), en donde: $1=$ $0 \% ; 2=1-10 \% ; 3=11-25 \% ; 4=26-40 \% ; 5=41-55 \%$ y 6 $=>56 \%$. La severidad se calculó como la suma de la escala individual de cada hoja por tratamiento / $(6 \times$ número de hojas evaluadas).

\section{Efecto del quitosano en la producción de peróxido de hidrógeno}

La producción de peróxido de hidrógeno a partir de especies reactivas de oxígeno, fue visualizado por la tinción de hojas que fueron recolectadas 6 horas después de los tratamientos con quitosano y colocadas en una solución de $3,3^{\prime}$ de diaminobencidina (DAB) $\left(1 \mathrm{mg} \mathrm{mL}^{-1} \mathrm{y} \mathrm{pH} 3.8\right)$, por 3 horas sin luz. Los tejidos fueron decolorados en etanol $(95 \%)$ en ebullición por $20 \mathrm{~min}$ (Thordal etal., 1997). Las imágenes fueron analizadas empleando el programa ImageJ (versión 1.49) y se expresó como porcentaje del área total (Abramoff et al., 2004).

\section{Efecto del quitosano en la actividad de la polifenoloxidasa (PFO) y peroxidasa (POD)}

La obtención del extracto enzimático se realizó de acuerdo al método descrito por Chen et al. (2000). La actividad de la POD se realizó mediante el protocolo propuesto por Chance \& Maehly (1955), con algunas modificaciones. La mezcla de la reacción incluyó $0.5 \mathrm{~mL}$ del extracto crudo (sobrenadante) y $2 \mathrm{~mL}$ de una solución amortiguadora de guayacol $(100 \mathrm{mM}$ de fosfato de sodio, $\mathrm{pH} 6.4$ y $8 \mathrm{mM}$ de guayacol). Posteriormente, se procedió a incubar por $5 \mathrm{~min} \mathrm{a} 30^{\circ} \mathrm{C}$. La reacción se detuvo añadiendo $1 \mathrm{~mL}$ de $\mathrm{H}_{2} \mathrm{O}_{2}(24 \mathrm{mM})$ y la actividad enzimática se determinó en un espectrofotómetro UV/visible (JENWAY 67 series), midiendo el incremento de la absorbancia a $460 \mathrm{~nm}$ cada $5 \mathrm{~s}$ durante 1:30 min. Por su parte, la actividad de PFO se determinó de acuerdo al método de Jiang (1999). La mezcla de la reacción fue de $0.5 \mathrm{~mL}$ del extracto crudo, $3 \mathrm{~mL}$ de catecol (100 mM de fosfato de sodio, pH 6.4, y $500 \mathrm{mM}$ de catecol), como sustrato y se midió el incremento de la absorbancia a $420 \mathrm{~nm}$ cada $10 \mathrm{seg}$ durante $3 \mathrm{~min}$. La actividad enzimática de la PFO y de la POD se expresó como Umg-1 de proteína, donde una unidad se manifestó como el incremento de la velocidad de la absorbancia por masa de proteína por minuto.
El contenido de proteína se determinó de acuerdo al método de Bradford (1976). La actividad enzimática se evaluó a diferentes tiempos después de la aplicación de los tratamientos $(0,24$, 48 y 72 horas).

\section{Diseño estadístico}

La evaluación de la germinación de esporas, severidad y producción del peróxido de hidrógeno, se llevó a cabo utilizando un diseño estadístico unifactorial; con el factor tratamiento a seis niveles. Los resultados se expresaron en porcentaje. Para el caso del efecto del quitosano en la actividad de la polifenoloxidasa y peroxidasa, se utilizó un diseño de bloques completamente aleatorizado, donde los bloques fueron las horas de evaluación. Todos los experimentos se llevaron a cabo por duplicado y se repitieron dos veces. Los resultados obtenidos fueron analizados mediante un análisis de varianza (ANOVA), se realizaron comparaciones de medias por una prueba de LSD de Fisher $(\mathrm{P}<0.05)$, con el paquete estadístico Statistica (versión 7).

\section{Resultados}

Análisis microscópico del efecto del quitosano en la germinación de esporas

De acuerdo al análisis estadístico todos los tratamientos con quitosano presentaron una diferencia estadísticamente significativa respecto al control (Figura 1). El quitosano al $0.01 \%$ fue estadísticamente diferente al resto de los tratamientos mostrando el menor porcentaje de germinación con tan solo un $18 \%$ en comparación con el tratamiento control $(95.6 \%)$.

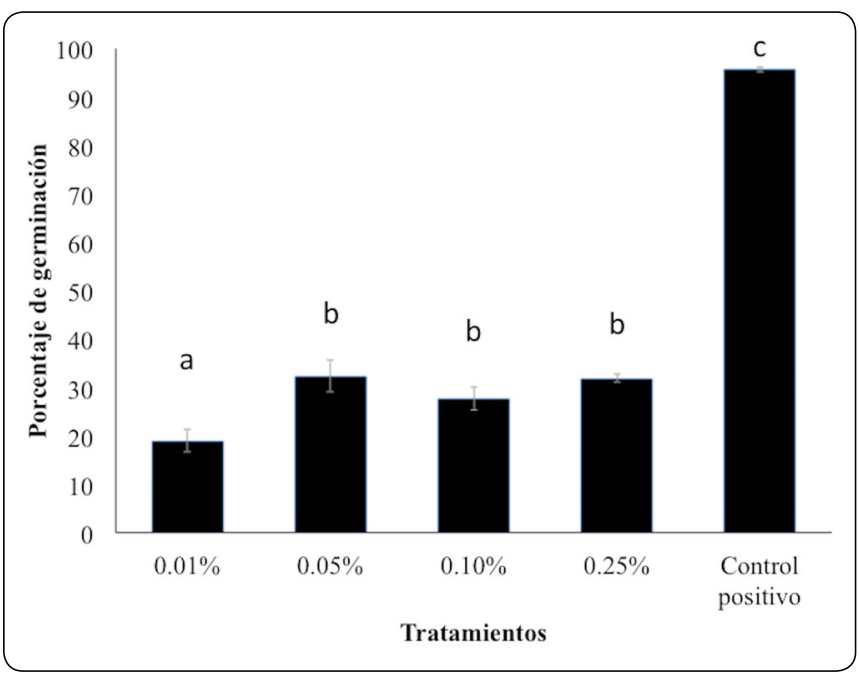

Figura 1. Germinación de esporas en plantas de jitomate $120 \mathrm{~h}$ después de la inoculación con Alternaria sp. tratadas con quitosano a diferentes concentraciones. Los valores se expresan como medias \pm desviación estándar $(n=15)$. Para cada tratamiento, los valores medios no seguidos por la misma letra minúscula son significativamente diferentes $(\mathbf{P}<\mathbf{0 . 0 5})$. 
Evaluación del efecto preventivo del quitosano en la severidad de la enfermedad

Como se muestra en la Figura 2, el daño foliar ocasionado por la enfermedad en el control superó el $50 \%$ de la superficie de la hoja, presentando manchas foliares café oscuras. Los tratamientos con quitosano fueron efectivos para reducir la severidad de los síntomas destacándose la efectividad de la concentración de $0.01 \%(\mathrm{P}<0.05)$, con respecto a las otras concentraciones evaluadas, coincidiendo con los resultados de la prueba de germinación.

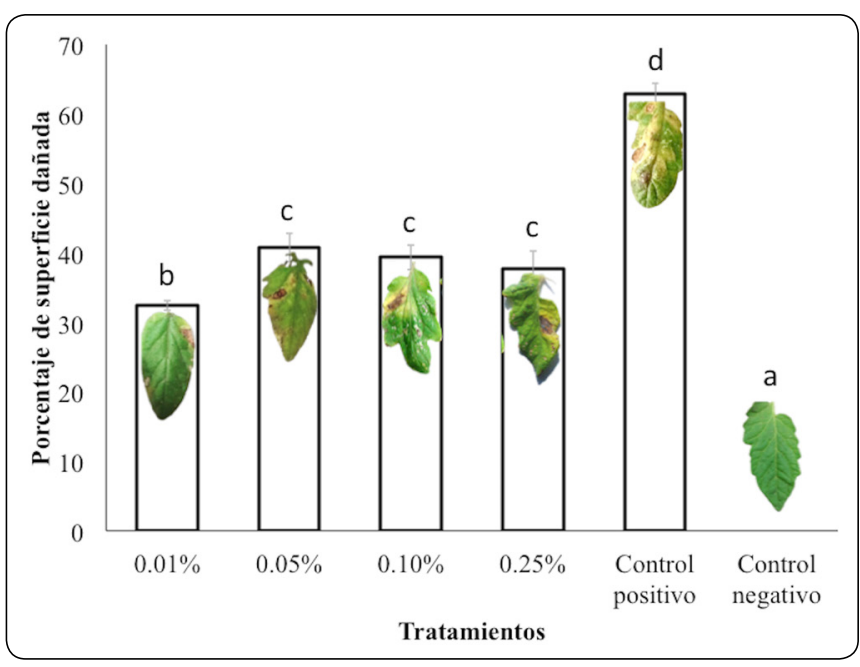

Figura 2. Efecto de la aplicación del quitosano sobre el daño foliar de las plantas infectadas con Alternaria sp. Los valores se expresan como medias \pm desviación estándar $(n=15)$. Para cada tratamiento, los valores medios no seguidos por la misma letra minúscula son significativamente diferentes $(\mathbf{P}<\mathbf{0 . 0 5})$.

Efecto del quitosano en la producción de peróxido de hidrógeno

Los resultados mostraron diferencias significativas $(\mathrm{P}<0.05)$, entre los tratamientos evaluados (Figura 3). El tratamiento con una mayor inducción en la producción de peróxido de hidrógeno fue la concentración de $0.01 \%$ con $26 \%$ de área inducida y el de menor inducción fue empleando la concentración de $0.25 \%$ con tan solo un $9 \%$. En el tratamiento del control positivo (patógeno) se obtuvo un $16 \%$.

Efecto del quitosano en la actividad de la polifenoloxidasa (PFO) y la peroxidasa (POD)

En todos los tratamientos con quitosano se incrementó la actividad enzimática de la PFO en comparación con el control negativo (asperjado con agua), de igual manera el control positivo también mostró mayor actividad a las $24 \mathrm{~h}$ de evaluación (Figura 4a). Respecto a la actividad de la POD, los tratamientos con quitosano al 0.25 y $0.1 \%$, así como el control positivo, muestran una diferencia significativa con los demás tratamientos (Figura 4b).

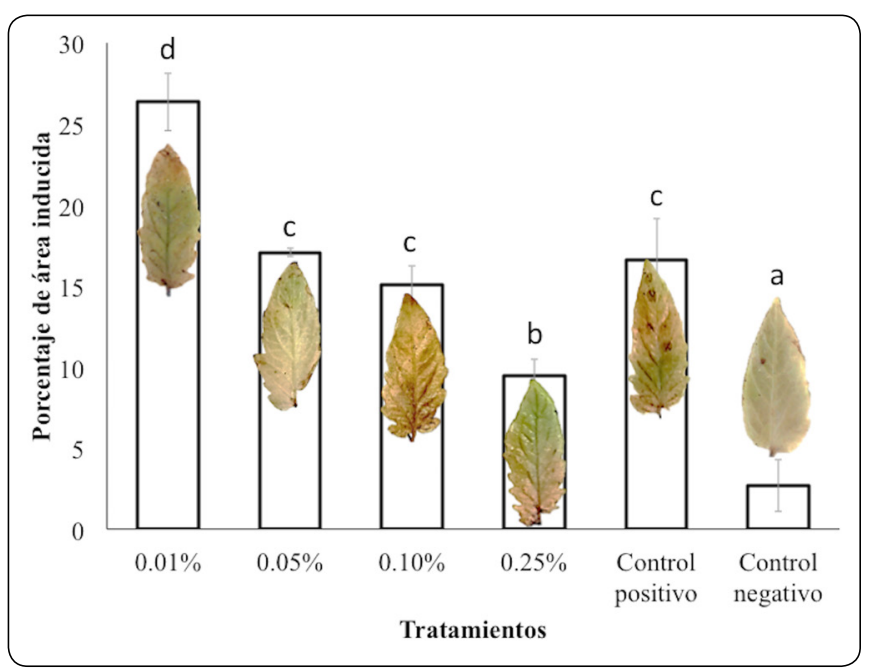

Figura 3. Efecto de la aplicación del quitosano a diferentes concentraciones en la producción de peróxido de hidrógeno. Los valores se expresan como medias \pm desviación estándar $(n=15)$. Para cada tratamiento, los valores medios no seguidos por la misma letra minúscula son significativamente diferentes $(\mathbf{P}<0.05)$.

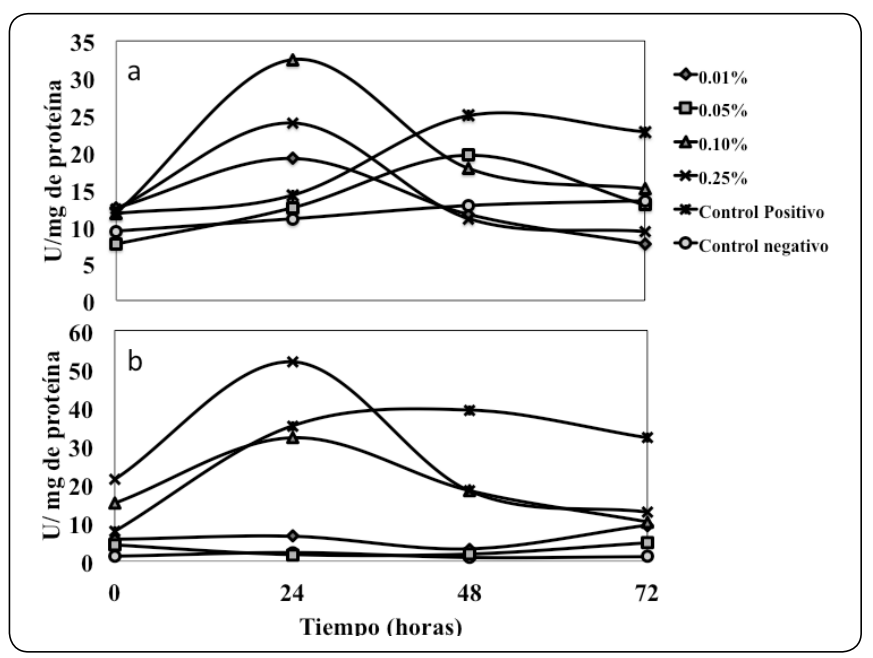

Figura 4. Efecto de la aplicación de tratamientos en la actividad enzimática: a) polifenoloxidasa y b) peroxidasa. Los valores se expresan como medias \pm desviación estándar $(n=15)$. Para cada tratamiento, los valores medios no seguidos por la misma letra minúscula son significativamente diferentes $(\mathbf{P}<0.05)$.

\section{Discusión}

La disminución en el proceso de germinación de esporas puede ser atribuible al efecto de barrera y antifúngico del quitosano sobre el patógeno. Los resultados de esta investigación coinciden con lo reportado por Chen et al. (2014), en frutos de jitomate tratados con quitosano infectados con A. alternata. Aún cuando ningún tratamiento pudo detener el establecimiento del fitopatógeno, los resultados muestran la efectividad del quitosano para reducir la severidad de la enfermedad. Lo anterior puede 
ser atribuido a los efectos del quitosano directamente sobre la espora debido al carácter catiónico, donde los grupos amino libres, cargados positivamente en medio ácido, interactúan con los residuos negativos de las macromoléculas expuestas en la pared celular de la espora, cambiando la permeabilidad de la membrana plasmática, lo que lleva a una alteración de su funciones principales afectando el proceso de germinación y establecimiento del fitopatógeno (Elsabee \& Abdou, 2013; Kong et al., 2010; Bautista-Baños et al., 2006). Los resultados de la investigación coinciden con lo reportado por Jayaraj \& Punja (2007), en donde asperjaron quitosano sobre plantas de zanahoria a una concentración de $0.02 \%$, logrando la reducción de la enfermedad ocasionada por Alternaria radicina en un $76 \%$. El peróxido de hidrógeno $\left(\mathrm{H}_{2} \mathrm{O}_{2}\right)$, es una especie reactiva de oxígeno que en las plantas puede ser generada mediante su exposición a factores bióticos o abióticos, así como mediante la aplicación de algún elicitor como el quitosano. (Kiirika et al., 2013; Zaninotto et al., 2006; Agrawal et al., 2002; Neill et al., 2002; Kauss et al., 1997). A baja concentración de quitosano $(0.01 \%)$ se observó una mayor eficacia en la producción de $\mathrm{H}_{2} \mathrm{O}_{2}$ y en la efectividad de este tratamiento para el control de la germinación de esporas y desarrollo de la enfermedad, probablemente debido a una mayor exposición del fitopatógeno al $\mathrm{H}_{2} \mathrm{O}_{2}$, sugiriendo que este proceso está involucrado en la defensa de la planta ante el fitopatógeno. Por otro lado, el control positivo muestra una producción de peróxido de hidrógeno, que es atribuido a la presencia del hongo; debido al reporte de que las especies reactivas al oxígeno son una línea de defensa de la planta ante los patógenos (Lehmann et al., 2015). Diversos estudios reportan que el quitosano puede inducir la producción de enzimas como la polifenoloxidasa y fenilalanina amonio liasa que participan en la producción de fitoalexinas (Yin et al., 2013; Rodríguez-Pedroso et al., 2009). La PFO cataliza la oxidación de compuestos fenólicos a quinonas (compuestos antimicrobianos), que son tóxicas para los patógenos (Soliva et al., 2000). Además, la PFO está involucrada en la lignificación de las células vegetales favoreciendo la defensa contra los fitopatógenos (Chen et al., 2014). La enzima POD realiza funciones de oxidación de compuestos fenólicos y lignificación de la pared celular de las plantas (Mohammadi \& Kazemi, 2002; Yin et al.,2013). Las peroxidasas por su parte, pueden contribuir a la resistencia inducida ayudando a generar $\mathrm{H}_{2} \mathrm{O}_{2}$ que tiene actividad antifúngica frente a diversos fitopatógenos (Peng \& Kuc, 1992). Es importante mencionar que el control positivo muestra un incremento en los niveles de polifenoloxidasa y peroxidasa ante la presencia y ataque del patógeno; ésto puede ser explicado debido a que se da lugar a una resistencia inducida por expresión diferencial de genes, en donde el reconocimiento específico como parte importante de la interacción plantapatógeno genera una serie de cambios metabólicos que son responsables de la activación de defensa ante el patógeno. Dentro de los mecanismos de defensa responsables de la resistencia se encuentran: la acumulación de metabolitos secundarios con actividad antimicrobiana, lignificación y acumulación de enzimas hidrolíticas, cuyo objetivo principal es detener el avance del patógeno (Jia et al., 2016; Mithöfer \& Maffei, 2016). Los resultados sugieren que la producción de la PFO y la POD en la planta, están involucrados como mecanismos de defensa ante el ataque del fitopatógeno y su presencia juega un papel importante para evitar el desarrollo del hongo.

\section{Conclusiones}

Todos los tratamientos con quitosano disminuyeron la severidad de la enfermedad ocasionada por Alternaria sp. La presencia del quitosano fue efectiva para activar mecanismos de defensa de las plantas mediante la producción de peróxido de hidrógeno, polifenoloxidasa y peroxidasa. La utilización del quitosano puede ser una estrategia para los métodos de control existentes y el manejo de enfermedades en plantas de jitomate.

\section{Agradecimientos}

Al Tecnológico Nacional de México/I.T. Tepic por el apoyo brindado para la realización del proyecto. El proyecto fue financiado por TecNM(proyecto 5854.16). AlConsejo Nacional de Ciencia y Tecnología (CONACYT), por la beca otorgada al estudiante Carlos A. Rodríguez Guzmán.

\section{REFERENCIAS}

Abramoff, M. D., Magalhaes, P. J., \& Ram, S. J. (2004). Image processing with Image. J. Biophotonics International., 11, 36-42.

Agrawal, G. K., Rakwal, R., Tamogami, S., Yonekura, M., Kubo, A., \& Saji, H. (2002). Chitosan activates defense/ stress response (s) in the leaves of Oryza sativa seedlings. Plant Physiology and Biochemistry, 40, 1061-1069. https:// doi.org/10.1016/S0981-9428(02)01471-7.

Arah, I. K., Kumah, E. K., Anku, E. K., \& Amaglo, H. (2015). An overview of post-harvest losses in tomato production in Africa: causes and possible prevention strategies. Journal of Biology, Agriculture and Healthcare, 5, 78-88.

Barnett, H. L., \& Hunter, B. B. (1998). Illustrated genera of imperfect fungi. Aps. Symp. Ser. (APS Press). https://doi. org/10.1007/s00299-007-0368-x.

Bautista-Baños, S., Hernández-Lauzardo,A.N., Velázquez-Del Valle, M. G., Hernández-López, M., Barka, E. A., BosquezMolina, E., \& Wilson, C. L. (2006). Chitosan as a potential natural compound to control pre and postharvest diseases of horticultural commodities. Crop Protection, 25, 108-118.

Bonner, M. R., \& Alavanja, M. C. R. (2017). Pesticides, human health, and food security. Food and Energy Security, 6, 89-93. https://doi.org/10.1002/fes3.112.

Bradford, M.M. (1976). A rapid and sensitive method for the quantitation of microgram quantities of protein utilizing the principle of protein-dye binding. Analytical Biochemestry, 72,248-254.https://doi.org/10.1016/0003-2697(76)90527-3

Carvalho, F. P. (2017). Pesticides, environment, and food safety. Food and Energy Security, 6, 48-60. https://doi. org/10.1002/fes3.108. 
Chance, B., \& Maehly, A. C. (1955). Assay of catalases and peroxidases. Methods in Enzimology, 2, 764-775. https:// doi.org/10.1016/S0076-6879(55)02300-8.

Chen, C., Belanger, R. R., Benhamou, N., \& Paulitz, T. C. (2000). Defense enzymes induced in cucumber roots by treatment with plant growth-promoting rhizobacteria (PGPR) and Pythium aphanidermatum. Physiological and Molecular Plant Pathology, 56(1), 13-23. https://doi.org/10.1006/ pmpp.1999.0243.

Chen, J., Zou, X., Liu, Q., Wang, F., Feng, W., \& Wan, N. (2014). Combination effect of chitosan and methyl jasmonate on controlling Alternaria alternata and enhancing activity of cherry tomato fruit defense mechanisms. Crop Protection, 56, 31-36. https://doi.org/10.1016/j.cropro.2013.10.007.

El Ghaouth, A., Arul, J., Grenier, J., \& Asselin, A. (1992). Antifungal activity of chitosan on two postharvest pathogens of strawberry fruits. Phytopathology, 82, 398-402.

Elsabee, M. Z., \& Abdou, E. S. (2013). Chitosan based edible films and coatings: A review. Material Science and Engineering: C, 33, 1819-1841. https://doi.org/10.1016/j. msec.2013.01.010.

Fagundes, C., Pérez-Gago, M. B., Monteiro, A. R., \& Palou, L. (2013). Antifungal activity of food additives in vitro and as ingredients of hydroxypropyl methylcellulose-lipid edible coatings against Botrytis cinerea and Alternaria alternata on cherry tomato fruit. International Journal of Food Microbiology, 166, 391-398. https://doi. org/10.1016/j.ijfoodmicro.2013.08.001,

INIFAP. Instituto Nacional de Investigaciones Forestales, A. y P. (2008). Jitomate. http://cesix.inifap.gob.mx/guias/ JITOMATE.pdf. Fecha de acceso: 3/04/2018.

Jayaraj, J., \& Punja, Z. K. (2007). Combined expression of chitinase and lipid transfer protein genes in transgenic carrot plants enhances resistance to foliar fungal pathogens. Plant Cell Reports, 26, 1539-1546.

Jia, H., Zhao, P., Wang, B., Tariq, P., Zhao, F., Zhao, M., \& Fang, J. (2016). Overexpression of polyphenol oxidase gene in strawberry fruit delays the fungus infection process. Plant Molecular Biology Reporter, 34(3), 592-606. doi: 10.1007/ s11105-015-0946-y.

Jiang, Y. M. (1999). Purification and some properties of polyphenol oxidase of longan fruit. Food Chemistry, 66, 75-79.

Kauss, H., Jeblick, W., Domard, A., \& Siegrist, J. (1997). Partial acetylation of chitosan and a conditioning period are essential for elicitation of $\mathrm{H}_{2} \mathrm{O}_{2}$ in surface-abraded tissues from various plants. Advances in Chitin Sciences, 2, 94-101.

Kiirika, L. M., Stahl, F., \& Wydra, K. (2013). Phenotypic and molecular characterization of resistance induction by single and combined application of chitosan and silicon in tomato against Ralstonia solanacearum. Physiological and Molecular Plant Pathology, 81, 1-12.

Kong, M., Chen, X. G., Xing, K., \& Park, H. J. (2010). Antimicrobial properties of chitosan and mode of action: a state of the art review. International Journal of Food Microbiology, 144, 51-63. https://doi.org/10.1016/j. ijfoodmicro.2010.09.012.

Lehmann, S., Serrano, M., L'Haridon, F., Tjamos, S. E., \& Metraux, J. P. (2015). Reactive oxygen species and plant resistance to fungal pathogens. Phytochemistry, 112, 54-62. https://doi.org/10.1016/j.phytochem.2014.08.027.

López-Mora, L. I., Gutiérrez-Martínez, P., Bautista-Baños, S., Jiménez-García, L. F., \& Zavaleta-Mancera, H. A. (2013). Evaluation of antifungal activity of chitosan in Alternaria alternata and in the quality of'Tommy Atkins' mango during storage. Revista Chapingo. Serie Horticultura, 19(3), 315-331.

McGovern, R. J. (2015). Management of tomato diseases caused by Fusarium oxysporum. Crop Protection, 73, 78-92. https://doi.org/10.1016/j.cropro.2015.02.021.

Mithöfer, A., \& Maffei, M. E. (2016). General mechanisms of plant defense and plant toxins. Plant Toxins, 3-22. https:// doi.org/10.1007/978-94-007-6464-4_21.

Mohammadi, M., \& Kazemi, H. (2002). Changes in peroxidase and polyphenol oxidase activities in susceptible and resistant wheat heads inoculated with Fusarium graminearum and induced resistance. Plant Science, 162, 491-498. https://doi.org/10.1016/S01689452(01)00538-6.

Neill, S. J., Desikan, R., Clarke, A., Hurst, R. D., \& Hancock, J. T. (2002). Hydrogen peroxide and nitric oxide as signalling molecules in plants. Journal of Experimental Botany, 53, 1237-1247.

Peng, M., \& Kuc, J. (1992). Peroxidase-generated hydrogen peroxide as a source of antifungal activity in vitro and on tobacco leaf disks. Phytopathology, 82, 696-699.

Rodríguez-Pedroso, A. T., Ramírez-Arrebato, M. A., RiveroGonzález, D., Bosquez-Molina, E., Barrera-Necha, L. L., \& Bautista-Baños, S. (2009). Propiedades químicoestructurales y actividad biológica de la quitosana en microorganismos fitopatógenos. Revista Chapingo Serie Horticultura, 15, 307-317.

Romanazzi G., Sanzani, S. M., Bi, Y., Tian, S., GutiérrezMartínez, P., \& Alkan, N. (2016). Induced resistance to control postharvest decay of fruit and vegetables. Postharvest Biology and Technology, 122, 82-94. https:// doi.org/10.1016/j.postharvbio.2016.08.003.

SAGARPA. Secretaría de agricultura, ganadería, desarrollo rural, pesca y alimentación. (2017).http://www.sagarpa.gob. $\mathrm{mx} /$ desarrolloRural/AsistenciaCapacitacion/Documents/ red del conocimiento/manuales pesa/invernaderos.pdf. Fecha de acceso: 4/04/2018.

Sathiyabama, M., Akila, G., \& Charles, R. E. (2014). Chitosaninduced defence responses in tomato plants against early blight disease caused by Alternaria solani (Ellis and Martin) Sorauer. Archives of Phytopathology and Plant Protection, 47, 1963-1973. https://doi.org/10.1080/0323 5408.2013.863497. 
Singh, S. (2016). Enhancing phytochemical levels, enzymatic and antioxidant activity of spinach leaves by chitosan treatment and an insight into the metabolic pathway using DART-MS technique. Food Chemistry, 199, 176-184. https://doi.org/10.1016/j.foodchem.2015.11.127.

Soliva, R. C., Elez, P., Sebastián, M., \& Martín, O. (2000). Evaluation of browning effect on avocado purée preserved by combined methods. Innovative Food Science and Emerging Technologies, 1, 261-268. https://doi. org/10.1016/S1466-8564(00)00033-3.

Thordal Christensen, H., Zhang, Z., Wei, Y., \& Collinge, D. B. (1997). Subcellular localization of $\mathrm{H}_{2} \mathrm{O}_{2}$ in plants. $\mathrm{H}_{2} \mathrm{O}_{2}$ accumulation in papillae and hypersensitive response during the barley-powdery mildew interaction. The Plant Journal, 11, 1187-1194. https://doi.org/10.1046/
j.1365-313X.1997.11061187.x.

Yao, H., Tian, S. \& Wang, Y. (2004). Sodium bicarbonate enhances biocontrol efficacy of yeasts on fungal spoilage of pears. International Journal of Food Microbiology, 93, 297-304. https://doi.org/10.1016/j. ijfoodmicro.2003.11.011.

Yin, L., Zou, Y., Ke, X., Liang, D., Du, X., Zhao, Y. \& Ma, F. (2013). Phenolic responses of resistant and susceptible Malus plants induced by Diplocarpon mali. Scientia Horticulturae, 164, 17-23. https://doi.org/10.1016/j. scienta.2013.08.037.

Zaninotto, F., La Camera, S., Polverari, A., \& Delledonne, M. (2006). Cross talk between reactive nitrogen and oxygen species during the hypersensitive disease resistance response. Plant Physiology, 141, 379-383. 